\title{
Climate change and green technology for enduring agriculture
}

\author{
Mihir Kanti Sarkar ${ }^{1}$, Md. Rajib Rahman ${ }^{2}$, G. M. Faysal Ahmed ${ }^{3}$, Ringko Kabiraj ${ }^{4}$, \\ ATM Jashim Uddin ${ }^{1}$, Ananya Biswas, ${ }^{5}$ Md. Humayan Kabir ${ }^{3}$ \\ ${ }^{1}$ Bangladesh Agricultural Research Council (BARC), Farmgate, Dhaka- 1215, Bangladesh \\ ${ }^{2}$ Soil Resource Development Institute (SRDI), Farmgate, Dhaka- 1215, Bangladesh \\ ${ }^{3}$ Ministry of Agriculture, Dhaka- 1000, Bangladesh \\ ${ }^{4}$ Bangladesh Computer Council (BCC), Sher-E-Bangla Nagar, Agargaon, Dhaka-1207, Bangladesh \\ ${ }^{5}$ Faculty of Agriculture, Patuakhali Science and Technology University (PSTU), Dumki, Patuakhali- 8602, Bangladesh
}

\section{Email address:}

mihircse@gmail.com (M. K. Sarkar),rahman.rajib_pt@yahoo.com (R. Rahman), faysal_5408@yahoo.com (G. M. F. Ahmed), rinku.bcc@gmail.com (R. Kabiraj), atm_uddin@yahoo.co.uk (A. J. Uddin), ananya.pstu@gmail.com (A. Biswas), mh.kabir.moa01@gmail.com (H. Kabir)

\section{To cite this article:}

Mihir Kanti Sarkar, Md. Rajib Rahman, G. M. Faysal Ahmed, Ringko Kabiraj, ATM Jashim Uddin, Ananya Biswas, Md. Humayan Kabir. Climate Change and Green Technology for Enduring Agriculture. American Journal of Agriculture and Forestry.

Vol. 2, No. 1, 2014, pp. 7-14. doi: 10.11648/j.ajaf.20140201.12

\begin{abstract}
Climate is the primary determinant of agricultural productivity. Given the fundamental role of agriculture in human welfare, concern has been expressed by federal agencies and others regarding the potential effects of climate change on agricultural productivity. Climate change is expected to influence crop and livestock production, hydrologic balances, input supplies and other components of agricultural systems. However, the nature of these biophysical effects and the human responses to them are complex and uncertain. Technology can be termed as the application of knowledge for practical purposes. In this context, technology allows people to become more efficient or to do things that were not possible before. To benefit from technology, it needs to be successfully linked with country's overall development objectives and applied to solving socio-economic problems. In this paper we propose some practical applications of green technology in agricultural production to regain the loss due to climate change.
\end{abstract}

Keywords: Agriculture, Climate Change, Green Technology, Knowledge

\section{Introduction}

Environmental technology is the key to conservation ecology, a science of protecting biological diversity. Conservation ecology also termed as conservation biology refers to the application of science to the conservation of genes, populations, species, and ecosystems.

The wastewater and sewage disposal has been major threat to human health in developing Asia. The liquid waste discharged by domestic residences, commercial properties, industry or agriculture generates potential contaminants and concentrations that to some extent is minimized or recycled in the developed world. It necessitates the adoption of available and affordable technology for renewable energy including sunlight, wind, rain, and geothermal heat, which are naturally replenished. The technologies that are available are solar power, wind power, hydroelectricity/micro hydro, biomass and bio fuels for transport. The importance for considering primary energy use (includes both renewable and non-renewable energy contained in raw fuels) is because about 13 per cent of world's primary energy comes from renewable sources, most of which comes from traditional biomass like wood-burning. The understanding of these energies helps us devise policies for sustainable development, which includes environmental sustainability, economic sustainability and socio-political sustainability.

\section{Friendly Technologies for Agriculture}

Widespread environmental degradation, severe poverty around the globe and the burning concerns about achieving and maintaining good quality of life were the principal factors for taking interest in intergenerational equity, in 
relation to access to natural resources. As most good agricultural land has already been farmed and the regions have exceeded the safe limit, primarily in Asia, the natural resources availability for further farming expansion is practically exhausted.

Furthermore, the pressure from worldwide urbanization, manufacturing and population growth necessitates a renewed commitment to clean energy and environment solutions. The need is a balanced mix of alternative energies and the development of new technologies. The advances in solar, wind, bio-fuels and energy efficiency design has speeded up the development on technology-driven energy and cost efficiency mechanism to justify economic growth. The strength and quality of the execution of public policy determines the proper use of renewable energy by protecting environment. There is no controversy in developing agriculture to obtain higher yield and increased income of the farmer without affecting the environment. This approach, in fact, is sustainable agriculture. Sustainability has been given due consideration because in Asian countries, land use has been intensified and problems such as, unplanned exploitation of the natural soil and water resources, have been realized. The skyrocketing costs of energy and agricultural inputs have reduced profitability, which has severely damaged the environment. This necessitates the proper assessment of the constraints and potentials of natural resources by examining policies of respective governments, and appropriateness of agro-technologies.

\section{Feasible Technologies}

\subsection{Solar Photovoltaic Technology}

Solar photovoltaic technology for instance, converts sunlight into electricity using semi conductor modules. Used generally for meeting lighting requirements, they can also be used for pumping water, refrigeration, communication, and charging batteries. Solar photovoltaic has application as green agricultural energy source for pumping water, street lighting in villages, lighting in rural houses and pest management.

\subsection{Wind Energy}

Wind energy is in a boom cycle. Overall, wind energy contributes only $1 \%$ of global electricity generation, but some countries and regions are already producing up to $20 \%$. Its importance is increasing since it produces less air pollutants and greenhouse gases compared to other conventional energy sources.

\subsection{Bio-Fuel}

Bio fuel, as bio-ethanol and bio diesel, has the potential to assume an important portfolio in future energy platter. Food security concerns and risks to environment and biodiversity are parameters that necessarily need to be assessed, while analyzing sustainability linkage of agriculture with bio fuel use. Also, conversion of wasteland to farmland with some crop options can be viewed as positive impacts. This area is going to be the hot cake for future research.

Biogas is the product of anaerobic digestion of organic matter by methanogenic bacteria. Biogas qualifies on the merits that this technology utilizes organic agricultural waste and converts it to fuel and fertilizer. Direct impacts of biogas are fuel-wood savings agriculture residue management, livestock manure, and kerosene savings. Increases in soil fertility and crop production have also been observed.

\subsection{Hydropower}

Hydropower plants ranging from $500 \mathrm{~kW}$ to $25 \mathrm{MW}$ capacities are conceived renewable. Generally, used in rural electrification, hydropower plants can take an equally important role in facilitating irrigation and value addition at source of agricultural products.

Some advanced technologies may also be used that are very much environment friendly for agriculture such as, Biomass, Improved Water Mills (an intermediate technology based on principle of traditional water mills), Geothermal technology, Bio Transgenics(BT) etc.

\section{Agriculture Technology and Poverty Reduction}

Agriculture plays a fundamental role in the economy of the least developed countries (LDCs), both in terms of size of an economic sector and element of a development strategy (Sadoulet and de Janvry 1995). It accounts for a large share of gross domestic product (GDP) (ranging from 30 to 60 per cent in about two thirds of them), employs a large proportion of the labor force (from 40 per cent to as much as 90 per cent in most cases), represents a major source of foreign exchange (from 25 per cent to as much as 95 percent in three quarters of the countries), supplies the bulk of basic food and provides subsistence and other income to more than half of the LDCs' population (FAO 2001). Since agriculture sector creates both forward and backward linkage through the income linkage, any shock in agriculture creates impact on the whole economy. Despite the importance of agriculture sector, the productivity of this sector is declining in underdeveloped countries. The per capita food production decreased by 0.8 per cent in 1980's and 0.1 per cent in 1990's (FAO, 2001). In the context of MDG to halve poverty by 2015 , it is imperative to increase benefit from agriculture sector, as there are volumes of evidences that increased agriculture productivity is the key to reduce poverty.

Continued agricultural growth is a necessity, not an option, for most developing countries, and this growth must be achieved on a sustainable basis so as not to jeopardize the underlying natural resource base or to impose costly 
externalities on others (Hagos, 2003). Gallup et al. (1997) found that every $1 \%$ increase in per capita agricultural output led to a $1.61 \%$ increase in the incomes of the poorest $20 \%$ of the population. Thirtle et al. (2001) concluded from a major cross-country analysis that, on average, every $1 \%$ increase in agricultural yields reduced the number of people living on less than US\$ 1 a day by $0.83 \%$. Hence, development of agriculture sector, defined in terms of increased production with decreased average cost, becomes prerequisite for the overall development of an underdeveloped economy.

World Bank in its World Development Report 2007 has laid emphasis to the agriculture development for poverty alleviation and has advised to put this sector in the centre of development agenda, if world wants to halve poverty by 2015. In the mean time economists have taken it as challenge to sustain and expand agriculture sector's unique poverty-reducing power. It is logical to assume that agriculture should itself be sustainable to keep and expand this power.

Sustainable agriculture integrates three main goals-environmental health, economic profitability, and social and economic equity. Sustainability of agriculture can be maintained in various ways. The decision, about which particular method or combination of methods to choose, varies from country to country and region to region. Some of the common ways towards sustainable agriculture are:

a) Integrated Pest Management (IPM)

b) Rotational Grazing

c) Soil conservation

d) Water quality/wetlands

e) Cover crops

f) Crop/ landscape diversity

g) Nutrient management

h) Agro-forestry

i) Marketing

The demand for cereals in the developing world is expected to increase by $59 \%$ in next 25 years. The data shows, the growth rate in cereal yields has declined from an annual rate of $2.9 \%$ in $1967-82$ to $1.8 \%$ in $1982-1994$ (Janvry, Graff and et al., 2000). The need for alternative agriculture technology is thus realized to increase the yield and meet the demand of increasing population.

In spite of major institutional changes and dramatic achievements in food security, the developing countries in Asia still house bulk of the world's poor. The new challenge is to improve food and nutrition security at the household level, poverty reduction and sustainable agriculture. The concern is the failure of technological innovation such as Green Revolution to prevent a steady decline in the growth of yields.

It is important to understand the relationship between technological change and well being of smallholder farm households. Literature has shown a robust and positive effect of agricultural technology adoption on farm household well-being. Technological change can make both the direct and indirect impact on reducing poverty. Increased production, higher gross revenues from higher volumes of sales, reduced production cost, lower yield risks, and improved natural resource management means an increased welfare to the farmers, which is the direct impact of innovation. The indirect impact is the reduced food price for net buyers, employment and wage effects in agriculture and other sectors of the economy and agriculture's contribution from foreign exchange earnings to overall economic growth.

\section{Selection of Technology}

In general, the seven criteria have been proposed to judge the appropriateness of technology by Robert $\mathrm{C}$. Wicklein in his paper entitled, "Design Criteria for Sustainable Development in Appropriate Technology: Technology as if People Matter". The issues have been analyzed in the present study by linking the strength or weaknesses of the stated technological applications to find out if they help in meeting the stated objectives. In other words, the current study attempts to use most of these criteria while assessing the technology for sustainable development.

a) System Independence: It is the ability of the technological device to stand alone for doing the required job. Whether the technology will require relatively more capital or labor will be analyzed to check system independence of the technology. Since, all three countries covered in the study are developing countries with high population pressure and unemployment, labor intensive technology will be system independence on the ground of cost. It is also kept in mind that required input for the technology is available or not.

b) Image of Modernity: People should perceive themselves as modern by adopting the technology. The message is people's realization that technological device can elevate the user's social status as well as need a basic human need. Image of modernity requires that the social status of people who adopt it either increases or remains unchanged. Although social status is contextual and is quite difficult to measure, it is common in all three countries that people who are member of social organizations have high social status. It has also been found that the people who are engaged in formal organization are more likely to adopt new technology. A study carried out by Yokoyama and Ali (2006) found that Malaysian rice farmers who are members of formal organization produce more rice. Similarly, Adhikari (2006) found that farmers with membership in social organization have more probability to adopt new technology. Similar evidences are available for India as well. Hence to check image of modernity, effort is made to analyze whether there is any probability that people with membership in formal organization refuse to adopt the technology.

c) Individual Technology vs. Collective Technology: It is the criteria to look into the societal/cultural standards in 
which the technology operates. In other words, it is the careful assessment of the technology that is based on group approach and becomes more system dependent. A society geared towards individual or single family unit will need more system independent technology. Collective technologies are more easily adopted as collective action reduces transaction cost. The success story of community forest in Nepal is an evidence to prove that collective technology relatively becomes more successful. Similar situation has been experienced in Malaysia and India.

d) Cost of Technology: Affordability of the technology is an important indicator for their wider use, since cost is the major factor in encouraging or discouraging the application of appropriate technology in developing economies. Although, the level of cost (high or low) is a relative concept, in all three countries labor is relatively cheaper than capital, and therefore, labor-intensive technologies are less costly.

e) Risk Factor: It is an important factor to find out how smoothly technology works in the local production system and the supportive system that explains to what degree is the technology system dependent or system independent. This indicates the need for understanding two types of riskboth the internal and external risk. Although analysis of risk is necessary before applying new technology, it is almost impossible to remove all risks. In this analysis risk, is considered on the basis of change in income level of people. If there is possibility of decreasing the income level of people then that technology will be more risky.

f) Evolutionary Capacity of Technology: If the chosen device is static, it will relatively reflect the short-lived solutions to a much larger problem. The technology, which supports the continuation of development by enhancing capability to expand, can be expected to compete at the regional, national and international level.

g) Single-Purpose and Multi-Purpose Technology: In contrast to single purpose technology, multipurpose technologies are the ones that furnish a variety of applications (e.g. a tiller that can be used for tilling the land, powering water pump, and drying rice).

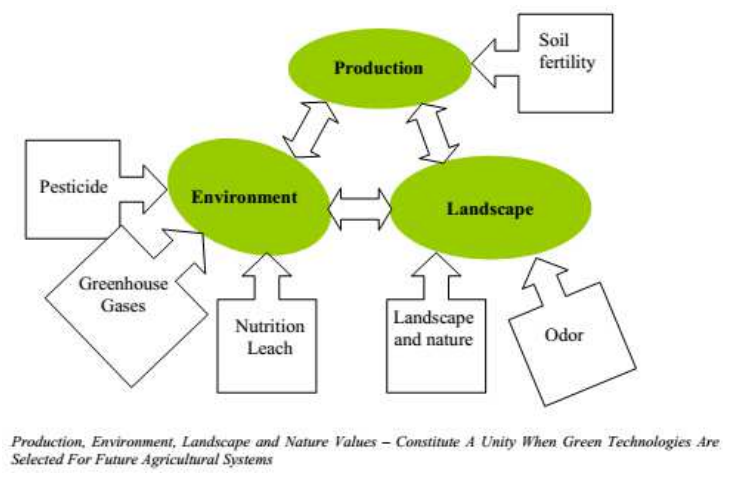

Figure 1. Three Bottom Lines
According to Borch et al. (2004) "The future environmentally friendly farming technologies are assessed and chosen in accordance with their contribution on three areas, where operating economical plans, green accounts and nature plans are treated equally." Components of Green Technology can be explained as shown in figure1.

\section{Situation Analysis}

The situation analyses of selected technologies in selected countries are made to find out how they are working, what are the costs and benefits and how the system can be sustained. In our analysis following factors are considered;

a) Current Performance: Performance of the technology is explained on the basis of their success and failure stories. The current performance has also been assessed on the basis of percentage share of population adopting particular technology.

b) Policy: Current government policy towards such technology has been identified. The review of selected regulatory measures in the chosen countries is made to find out their strengths and weaknesses to facilitate GT initiative and recommendations are made to develop favorable regulatory frameworks for the further development of GT.

c) Cost-Benefit: Cost-Benefit analysis of the technology has been carried out. A detailed cost-benefit analysis with valuation in quantitative technique is not possible due to time constraint. So components of costs and benefits along with risk factors and externalities have been identified.

d) Performance Indicator: The performance and sustainability of the technology has been reviewed. Therefore, the operational, technical, economical and environmental aspects of the selected technology have been considered.

\section{Structure of Energy Consumption in Bangladesh}

Dhaka has made the estimation of greenhouse emissions from the fuel combustion in Bangladesh. The United States Country Studies Programme (USCSP) also states that GHG inventory was constructed, the mitigation options of $\mathrm{GHG}$ emissions in energy sector were identified and vulnerability assessment for water resources and agriculture were carried out. The result shows that GHG emissions and per capita GHG emissions for Bangladesh is relatively very small in the region. One of the reasons for low GHG emissions is negligible percentage share of thermal (diesel and coal) power generation, the major contributor of GHG emissions, in Bangladesh. Thousand tons of oil equivalent. 
Table 1. Structure of Energy consumption, Bangladesh

\begin{tabular}{|c|c|c|c|c|c|c|c|}
\hline Energy Source & 2005-06 & 2006-07 & 2007-08 & 2008-09 & 2009-10 & 2010-11 & 2011-12 \\
\hline Traditional & 7,397 & 7,544 & 6,377 & 5,989 & 5,674 & 5,213 & 4,678 \\
\hline Fuel Wood & 6,956 & 7,153 & 6,578 & 6,143 & 5,768 & 5,463 & 4,978 \\
\hline Agricultural Waste & 465 & 480 & 435 & 413 & 345 & 375 & 351 \\
\hline Animal Dung & 576 & 614 & 598 & 534 & 456 & 414 & 365 \\
\hline Commercial & 1,654 & 1,567 & 1453 & 1378 & 1234 & 1134 & 1098 \\
\hline Coal & 203 & 197 & 201 & 187 & 154 & 143 & 133 \\
\hline Petroleum & 867 & 813 & 734 & 712 & 684 & 657 & 634 \\
\hline Electricity & 185 & 197 & 187 & 175 & 163 & 152 & 123 \\
\hline Others & 68 & 65 & 68 & 61 & 63 & 57 & 54 \\
\hline Total & 18,371 & 18,630 & 16,631 & 15,592 & 14,541 & 13,608 & 12,414 \\
\hline
\end{tabular}

\section{The use of Information and Communication Technology (ICT) for Facilitating Green Technology}

While information and communication technologies could add little direct value to agricultural yield, possibilities also are that they can be the centre of paradigm shifts.

Since, GT has emerged as a strong force to influence climate change and build globally based, environmentally sustainable solutions, organizations are using ICT to reduce carbon emissions and develop and support business models with a green focus. This relationship is considered while ICT is recommended to serve as a green technology.

It is believed that the use of ICT improves energy efficiency in the economy, starting with buildings, lighting and the power grid. ICT enables economy a green behavior. For example, the most advanced computer servers consume the same amount of energy as a standard light bulb; if widely used they can offer potential energy savings up to $70 \%$. The European Commission presumes that real gains from green ICT will come from developing energy efficient ICT solutions that impact the other $98 \%$ of global emissions (http://europa.eu/rapid/pressReleasesAction.do?referenc $\mathrm{e}=\mathrm{IP} / 08 / 733$ ). The intention of elaborating ICT in the present Green Technology is in this context.

Precision agriculture uses information and communication technologies (ICT) to cover the three aspects of production namely, a) for data collection of information input through options as Global Positioning System (GPS) satellite data, grid soil sampling, yield monitoring, remote sensing, etc; b) for data analysis or processing through Geographic Information System (GIS) and decision technologies as process models, artificial intelligence systems, and expert systems; c) and for application of information by farmers. Adjustments in volume and timing of fertilizer and pesticide inputs and limited input leakage to environment are expected in precision agriculture (Hrubovcak, 1999). ICT can also be useful in knowledge intensive farm management as IPM. Global Plant and Pest Information Services of FAO http://www.ecoport.org, United States' Department of Agriculture's National IPM Network at http://www.ipmcenters.org/index.cfm, North American
Plant Protection Organization's Phytosanitary Alert System http://www.pestalert.org/index.cfm? NAPPO Language Pref='English' are some information portals for IPM. Opportunities to link niche products and producers to markets can also give impetus to low input indigenous agricultural production.

The Government of Nepal's Information and Technology Act 2004 supports ICT intervention for agricultural development and environmental management (ITP, 2004). Ninth Malaysian Plan commits to use of ICT for providing access to market and trading information. Supply and Demand Virtual Information (SDVI) system, e-trade, and Agribazaar portals, Medan InfoDesa facilities are expected to support agro marketing. (NMP, 2006).

\section{Case Studies}

\subsection{NEPAL: Biogas}

In the simple words biogas, a combustible gaseous mixture primarily of methane and carbon dioxide, is a product of anaerobic digestion of organic matter by methanogenic bacteria. When produced under controlled conditions inside a biogas plant, it can serve to meet energy requirements for cooking, lighting, refrigeration, electricity generation, and internal combustion engines. Slurry or digested effluent from biogas plant has high fertilizer value. Both energy and agriculture products of biogas technology and its minimal adverse environmental implications make it an appropriate green agricultural technology. Revived biogas sector of Bangladesh is the result of a consolidated effort of public and private stakeholders; and donor agencies. Establishment and institutionalization of the elements of biogas industry in Nepal further suggests an appropriate and inclusive scheme for renewable energy promotion to all strata of the society. Biogas Support Programme (Phase I-IV) has been instrumental in promotion of biogas in Bangladesh.

Biogas has links with agriculture, forest, environment and overall livelihood of the people. These links can be shown with the aid of following figure 2. Biogas can be deployed to increase incomes and save the environment and has great impact on the health and time saving for women and children. 


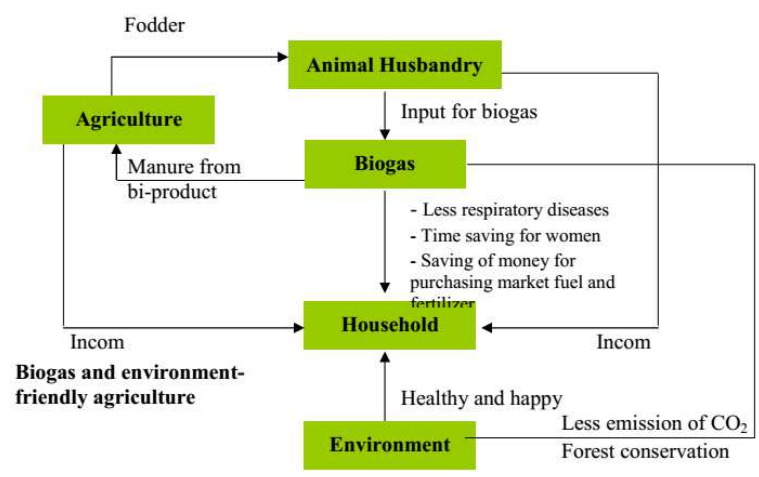

Figure2. Sustainability and Biogas

\subsection{Agro-Forestry and Environment-Friendly Agriculture}

Adoption of agro-forestry technology improves the various environmental components of agriculture. Some of them are resource conservation, carbon sequestration, biodiversity conservation, improvement in soil fertility and structure etc. Agro-forestry helps to improve the soil fertility through (Rai and Handa, NA):

a) More efficient nutrient cycling within the system and consequently more efficient utilization of nutrient that are either inherently present in the soil or externally applied;

b) Biological nitrogen fixation and solubilization of relatively unavailable nutrients;

c) Increase in the plant-cycling fraction of nutrients, with their resultant reduction beyond the nutrient-absorbing zone of the soil;

d) Complementary interaction between the component species of the system, resulting in a more efficient sharing of nutrient resources among the components;

e) Enhanced nutrient economy, because of different nutrient-absorbing zones of the root system of the component species;

f) Moderating effect of additional soil-organic matter on extreme soil reactions and consequently improved patterns of nutrient- release ability.

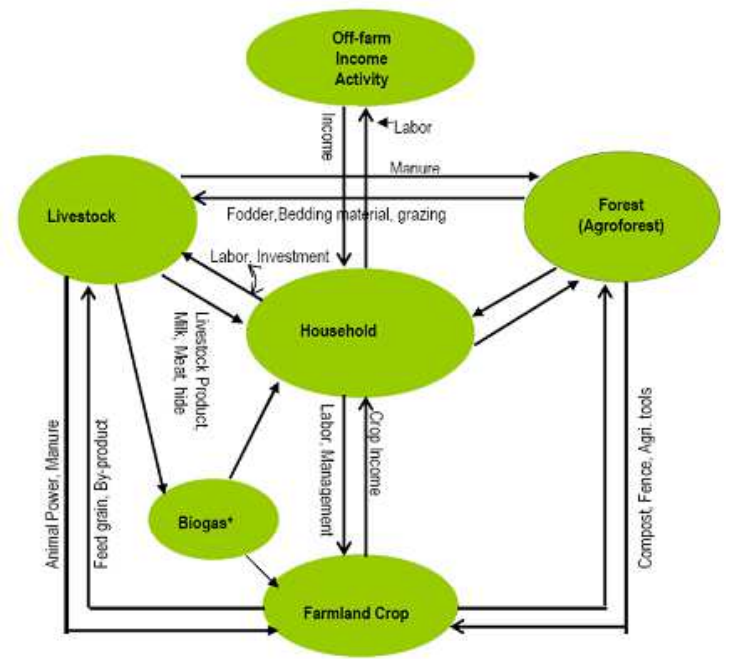

Figure 3. Inter-Linkages of Agro forest, Agriculture, Household and Livestock
There is indirect benefit of agro-forestry for environment friendly agriculture through the route of agro-forestry=> livestock $=>_{\Gamma}$ biogas $=>$ environment friendly agriculture.

\section{Impact of Green Technology}

There is an international call for all types and sizes of enterprises- government, non-government to not-for-profits to promote sustainable and environmentally responsible business practices. These enterprises can collectively jump on the "green" bandwagon. The message for increasing market opportunities for their products can be disseminated through environmental-awareness initiatives. The advantage of reducing the impact of climate change through the reduction of carbon footprint can be explained by creating awareness about new technologies. The awareness is helpful in understanding market trends, environmental threats and opportunities.

Recently, a new Green Technology Initiative (GTI) has been launched in London to help IT stakeholders to limit environmental impact of their IT infrastructure. In other words, it means limiting the carbon emissions associated with IT equipment. Reducing the carbon footprint is in line with British Governments' target of a $20 \%$ reduction in greenhouse gas emissions by 2020 . There is an overwhelming interest in making the system greener, but majority lack information on how to do it?

Non-sustainable land-use practices and highly erosive monsoon rains are the contributing factors for low agricultural productivity and hence high incidence and severity of poverty in many parts of Asia. The discussion on sustainable agriculture becomes incomplete if we do not consider environmental degradation in the context of development. Sustainability should also be resource-saving, not one-sided resource usages. Rapid growth of urbanization and increasing demand has made the poor a victim of natural resource degradation largely in the form of shortage of fuel, fodder, and drinking water.

Since, energy improves productivity in major sectors of the economy that contributes to GDP, it can create employment and increase income. With backward agriculture and high poverty levels, the policy for making choices of the appropriate alternative energy technology is very important. The per capita energy consumption in developing countries stands at 400 units as against a minimum of 8000 units in developed world. The possibility of improving per capita energy consumption levels is through renewable energy technologies.

\section{Discussion}

An overview of the challenges and relevant options are briefly elaborated in this section. There is a consensus that although there is a strong business case for "sustainability", it is one of the most difficult and complex tasks to balance environmental and business concerns. In other words, there is a problem in balancing between the societal benefits of 
"green" practices and regulations with their costs. This situation is elaborated by Professor Jim Sweeny by saying "....in at least two crucial areas - energy management and materials management - a gap remains between societal benefits and private business benefits".

Storms, floods, droughts and wildfires are the results of climate change. We know the earth's average temperature has risen by 0.7 degree Celsius since pre-industrial times. As $\mathrm{CO}_{2}$ emissions are the major factor for causing climate change, the major task is to adopt energy demand reduction measures and significant growth in renewable energy for reducing $\mathrm{CO}_{2}$ emissions.

The use of technologies at the status quo level will create health hazards to the people and other life that inhabits the planet. The Inter-governmental Panel on Climate Change (IPCC) in its Fourth Assessment Report outlines human activity for creating scary effects of climate change to damage the world environment. This scenario necessitates the early success in deploying renewable carbon-free technologies by moving away from the coal and oil based economy to solar, wind, nuclear, bio-fuels, hydroelectricity, batteries, hybrid cars, etc. Efforts in recent years are found in building giant space mirrors to reflect solar radiation back into space for commercializing renewable energy.

As the adverse impact from climate change in ecosystem, agriculture, fresh water and human health is going to be the major threat, APCAEM countries need to immediately prepare themselves for need-specific alternative technologies. It is advisable to seeking technical and financial support from relevant UN agencies in capacity building programs for the mitigation of unforeseen eventualities.

Although rich countries can relatively take more benefits from renewable sources to meet their energy demands, it seems extremely difficult to derive adequate electricity or liquid fuels to sustain the current high per capita rates of consumption from renewable sources. This suggests the fact that sustainable future may be possible only when we get success in significantly reducing current material "living standards" and in gross economic activity. The limitations of conventional energy sources are as such that resources for power generation i.e., coal, gas, etc. are limited. Solar photovoltaic (PV) technology facilitates in converting the solar energy to electrical energy and is being used for applications such as lighting, water pumping, communication systems, remote area village's electrification, telecom applications, traffic signaling and railway signaling systems. This system has proved to be effective in rural electrification projects around the world. The fundamental problem of $\mathrm{PV}$ is the inadequate information on the potential and limitations of its application. Therefore, unless the potential contribution of PV to rural development and poverty alleviation is not properly examined, it will be difficult for the developing countries to make financial as well as political commitment.

\section{Conclusion}

The review shows when used correctly agro-environment-friendly technology has promoted sustainable agriculture growth and reduced widening rural-urban income disparities. The application of green technology is the answer for sustainable development but poor countries have not been able to use applicable technology largely because of their inability to afford to the available alternatives. Efforts are needed to align economic development policies with the goal of increasing the realization of human capabilities. GT in the reviewed countries has mostly minimized environmental hazards and made farmers more productive through enhanced efficiency. The lesson that has been drawn from this study is since distributive structure and property system especially in India and Nepal is not very satisfactory, care should be given to access land and credit; the access in health, the access in clean water and education; and above all the access in employment.

In assessing the applied technologies, it was realized that sustainable agriculture as defined and elaborated by FAO was resource conserving; environmentally non-degrading; technically appropriate; and economically and socially acceptable. However, as it is generally agreed in case we fail to precisely define the scope of work, the term "sustainability" becomes both ambitious and ambiguous.

The greater is the chance of the failure of macroeconomic policies; the worse is the case in income inequality. If the policies on food security and income generation fail to address poverty and malnutrition, the objective of elevating economic status of majority of the poor at the individual and household level through the application of green technology remains incomplete. The major concern of the United Nations through the use of agricultural technology is therefore, to guarantee the distribution of the benefits of increased agricultural productivity rather equitably.

Information technologies and their inter-linkages with agro-food sector are vital to understand the strength of pro-poor and environment-friendly agricultural technology. An open debate needs to be organized and facilitated at regular intervals on the need for investment in the technology, reason for their acceptance, strength and weaknesses for the adoption, and investigating the reason for their rejection.

In terms of the use of electronic equipment, the weak regulatory measures (regulation, directives, and standards) especially on the purchase, operation and disposal, has attracted interest on the global political agenda about the environmental impact of the electronics industry. Although the adoption of technology and regulatory compliance is on the average painful in the developing world, there are many valuable business benefits to be gained by opting for "greener" power. Examples from selected countries have revealed clearly that GT reduces operational cost.

Electronic communication networks as a powerful information infrastructure connects enterprises and 
knowledge bases. As the new information system has been developed as a parallel traditional physical world, the development of its infrastructure to connect indigenous practices into the modern system should be given top priority.

The present study shows adoption of Green Technologies have increased agricultural output without depleting presently available resources beyond the point of recovery. Though selection of technology is by default condition dependent one or the other renewable energy technology and green agriculture strategy can in all circumstances be pragmatic. Inter linkages of technologies with society should be deliberated in advance to access their roles in achieving the expected outcomes. The review on alternates shows an assessment should not occur in isolation. Instead, implications on income and opportunity creation; output, input, and ecological balance, gender equity, etc. should be considered with due attention. Green technologies assure potency for sustainable agricultural growth but significant effort will be required to substitute conventional practices.

Several studies have shown food production among small landholders is positively correlated to the increased use of industrial inputs and marketing opportunities for food crops. This demands a favorable macro environment that allows farmers to enhance the use of inputs. A concerted effort is, therefore, needed to create environment that helps farmers connect safely with market, making them able to avoid externality.

\section{Acknowledgements}

First of all we consign our limitless thanks to the Almighty God for giving us strength, endurance and ability to complete this research.

We would like to express our deepest gratitude to our colleagues for their direct and indirect help for completion the research on "Climate change and Green Technology for enduring Agriculture".

\section{References}

[1] J.W. McKinsey- Jr, R.E. Evenson, "Technology-Climate interactions in the green revolution in India" center discussion paper no.805, Economic growth center, Yale University.

[2] D. Schüller, "On the Optimal Allocation of Green Technology under Climate Change Agreements", FNI Report 8/2009, Fridtjof Nansen Institute, N-1326 Lysaker, Norway.

[3] P.F. Moore, B.J. Parai, "THE GREEN REVOLUTION", Technology in Contemporary Society.

[4] K. P. O. Brien, S. Franjevic, J. Jones, "Green Chemistry and Sustainable Agriculture -The Role of Bio pesticides" Advancing Green Chemistry September, 2009.

[5] Aikens, M. T., A. E. Havens et al. (1975). The Adoption of Innovations: the Neglected Role of Institutional Constraints. Department of Rural Sociology, Ohio State University.

[6] Amatya, S.M. and Newmann, S.M.(1993). Agroforestry in Nepal: research and practice. Agro forestry Systems, 21: 215--222, 1993.

[7] Bartlett, A. (2005). Farmer Field School to Promote Integrated Pest Management in Aisa: The FAO Experience available at http://www.communityipm.org/downloads.html.

[8] Wang, X. and Z. Feng. (1994. Atmospheric Carbon Sequestration through Agro forestry in China. Energy: 20(2).

[9] Regmi, B. (2003). Contribution of agroforestry for rural livelihoods: A case of Dhading District, Nepal. Paper Presented at The International Conference on Rural Livelihoods, Forests and Biodiversity 19-23 May 2003, Bonn, Germany.

[10] Pehu, E. and C. Ragasa, (2007).Agricultural Biotechnology Transgenics in Agriculture and their Implications for Developing Countries. Background Paper for World Development Report 2008, The World Bank.

[11] Neill, S. P. and D. R. Lee. (2001). Explaining the Adoption and Disadoption of Sustainable Agriculture: The Case of Cover Crops in Northern Hounduras. Economic Development and Cultural Change 49(4): 793-820. 